\title{
LITERATURA, TERRITÓRIO E IMAGINÁRIO A AUSÊNCIA DA PALAVRA SERTÃO NOS ROMANCES DO RIO GRANDE DO SUL
}

\author{
Maria Lúcia Ribeiro Vilarinhos \\ Coordenação de Geografia do IBGE
}

\begin{abstract}
Resumo
Este trabalho é parte do projeto Atlas das representações literárias de regiões brasileiras, desenvolvido na Coordenação de Geografia do IBGE. O primeiro volume, em fase de lançamento, intitula-se Brasil Meridional. Os volumes 2 e 3 abordarão os Sertões Brasileiros. A proposta desse projeto é identificar em obras da literatura nacional regiões que a geografia identificou a partir de sua metodologia científica, e representá-las em mapas de diferentes escalas, fotos e imagens de satélite. Ao longo da produção do primeiro volume, que implicou na leitura de inúmeras obras de variados autores do Rio Grande do Sul, chamou a atenção a ausência da palavra sertão na trama dos romances, ainda que, com freqüência, tais obras abordassem o processo de ocupação daquele território. $\mathrm{O}$ presente trabalho procura levantar algumas hipóteses para este fato, partindo da própria discussão do significado da palavra sertão, bem como da configuração do território em questão e, ainda, do contexto em que se deu a sua ocupação. O objetivo é confrontar os significados atribuídos ao termo com uma situação específica - o território do Rio Grande do Sul - buscando aferir a coerência desta significação, ao mesmo tempo em que se pode avaliar a relação entre discurso ficcional e realidade.
\end{abstract}

Palavras-chave: Sertão; Literatura; Região Geográfica e Rio Grande do Sul.

\begin{abstract}
This work is part of the project Atlas of literary representations of Brazilian regions, developed by the IBGE Geography Coordination. The first volume is in its launching phase, and is called Meridional Brazil. Volumes 2 and 3 will deal with the Brazilian 'Sertões'. The project aims at identifying regions in Brazilian literary works already identified by geography based on scientific methods, representing them in maps of different scales, photographs, and satellite images. During the production period of the first volume, which involved the reading of a number of works by various authors from the State of Rio Grande do Sul, the absence of the word 'sertão' was noticed, even though such works frequently dealt with the occupation process of this territory. This paper attempts at offering some hypothesis to explain this fact, beginning with the discussion of the meaning of the word 'sertão', and the configuration of its respective territory, as well as the context of its occupation. The goal is to compare the meanings ascribed to the term 'sertão' with a specific situation - the territory of the State of Rio Grande do Sul - in order to asses the coherence of the meaning, evaluating at the same time the relation between ficcional discourse and reality.
\end{abstract}

Key Words: Sertão; Literature; Geographic Region, and State of Rio Grande do Sul.

\section{$\circ \bigcirc \circ$}

\section{SERTÃO}

Citando diferentes fontes Rodrigues (2003) indica que "a palavra sertão advém do termo latino desertanum, desertum", e foi empregada para "designar lugar desconhecido, solitário, seco e não entrelaçado ao conhecimento.” Assim, o termo sertão teria sido incorporado à língua portuguesa para designar lugares distantes, desconhecidos, no interior do continente.

Para Moraes o sertão não pode ser definido por características do quadro natural, tão pouco pela transformação decorrente da ocupação humana e seria, antes,

uma condição atribuída a variados e diferenciados lugares. Trata-se de um símbolo imposto - em certos contextos históricos - a determinadas condições locacionais, que acaba por atuar como um qualificativo local básico no processo de sua valoração. Trata-se de um discurso valorativo referente ao espaço, que qualifica os lugares segundo a mentalidade reinante e os interesses vigentes nesse processo."(MORAES, 2002, p. 361, 362) 
Waibel, por sua vez, ao conceituar zona pioneira e comparar os processos de expansão da fronteira nos Estados Unidos e no Brasil, definiu sertão como uma área desbravada por caçadores, extrativistas e criadores de gado que

criaram um tipo de paisagem que por longo tempo não era nem terra civilizada nem mata virgem, .... No sertão brasileiro, as condições de vida primitiva e sem organização, que transitoriamente encontramos em todas as frontiers, tornaram-se um aspecto permanente.”(WAIBEL, 1979, p. 281)

As duas últimas definições destacam o fato de que o sertão não é um lugar específico, mas a condição de alguns lugares. Tal condição seria ensejada por interesses valorativos em relação aos lugares em questão, interesses estes que variam ao longo do tempo. Assim, partindo destas definições, é possível supor que diferentes segmentos territoriais em nosso país receberam a alcunha de sertão por constituírem área sobre a qual atuavam intenções relativas à sua não ocupação, ou de seu entorno, pelo menos no momento em que foram incorporadas ao território nacional.

Um outro aspecto também apontado por Moraes deve ser levado em conta. Se o sertão se define por uma condição, é preciso que exista o contraponto a esta condição. Segundo o autor

Para existir o sertão é necessária a existência de lugares que não sejam englobados nessa denominação, que apresentem condições que exprimam o oposto do qualificado por tal noção. Daí ela sempre se apresentar numa formulação dualista, como parte de uma realidade vista como cindida e dual, na qual a condição sertaneja ocupa a posição negativa ou subordinada." (MORAES, 2002, p. 363)

Tomando todas estas características e não restringindo a compreensão do termo ao quadro natural, nada impede que, a princípio, possamos encontrar lugares que apresentem a "condição sertaneja" no sul do Brasil, mais especificamente no Rio Grande do Sul. É preciso destacar que o termo sertão ocorre em textos literários do Paraná, o que exclui a vinculação imediata de seu significado a lugares secos ou áridos. O trecho a seguir é extraído do romance de Domingos Pellegrini , Terra Vermelha, sobre a ocupação do Norte do Paraná.

(A mata) era mesmo mais alta que a do lado de lá, uma parede verde onde a estrada se enfiava estreita como uma fita vermelha no verde.

(...) Só então entendeu também por que diziam sertão do Tibagi: dali até o rio Paraná eram trezentos quilômetros de mata, um deserto de gente, apesar de tanto bicho"(PELLEGRINI, 2003, p. 96, 97).

Como se vê, a aridez não é, de fato, uma condição intrínseca a lugares designados como sertão, sendo a distância em relação a áreas mais densamente povoadas, assim como o pouco conhecimento que se possa ter sobre o lugar, elementos que com maior freqüência estão associados à idéia de sertão.

\section{LITERATURA SUL-RIOGRANDENSE}

Nos textos literários sobre a ocupação do Rio Grande do Sul, ainda que se fale de áreas distantes dos centros de povoamento, desconhecidas e perigosas, não se registra o uso da palavra sertão para denominálas. Tal fato poderia estar associado à condição física do território, que se caracteriza pela ocorrência de extensos terrenos levemente ondulados, com um horizonte de visibilidade bastante dilatado?

Tomemos alguns exemplos de passagens de romances gaúchos, em que surge a relação entre os habitantes e as características deste território.

É comum encontrarmos em textos literários do Rio Grande do Sul passagens que demonstram o quanto a paisagem típica deste estado marca a vida de seus habitantes. Mais especificamente quando o cenário em que se passa a ação é a Campanha Gaúcha, como se pode constatar nos trechos a seguir: 
Um dia, o improvisado grumete Phillip, do alto da sua gávea, gritou que enxergara um ponto negro e movediço que vinha naquela direção. Houve uma correria lá embaixo, o pai e a mãe dando ordens que ninguém entendia. Temiam que fossem soldados da Banda Oriental, internados já em território da Província, quem sabe até os inimigos mencionados pelos dois soldados na Medanos-Chico. (GUIMARÃES, 1972, p. 27)

Phillip avistou vultos vindos do Rio Grande e deu o aviso costumeiro lá do alto. Começou a correria. Quando o piquete de soldados brasileiros chegou, tudo transcorria normalmente... e duas horas depois desapareciam no rumo do Chuí.(GUIMARÃES, 1972, p. 54)

Nisto, a Tita falou:

- Lá apontou um.

Atenderam todos na direção que o dedo da menina mostrara. Guedes se levantou. E depois de observação demorada, declarou não conhecer o que vinha vindo e acrescentou ainda que lhe parecia não ser gente de por ali.’(MARTINS, 2001, p. 22)

À frente, o descampado. À esquerda o mar, que não víamos, mas escutávamos no rugir de suas ondas. (...) Depois de pouca marcha, chegamos ao forte de São Gonçalo, menor e mais pobre que o do Rio Grande, mandado construir pelo Gomes Freire às margens do canal que liga a Lagoa Mirim com a dos Patos.

(...) Daí por diante, a amplidão.

As noites estreladas, onde o frio não dava trégua, entrando pela nossa pele, arroxeando os dedos e a ponta do nariz.’(ASSIS BRASIL, 1997, p. 105)

Em todas as passagens anteriores ficam evidentes, por um lado, a amplidão do horizonte que se descortina, por outro, trata-se de áreas fracamente povoadas, grandes vazios demográficos onde é possível distinguir a aproximação de estranhos a longas distâncias.

Esta particularidade do território do Rio Grande do Sul - a extensa área de ondulações muito discretas, que permitem uma visibilidade não menos extensa do que se passa nos arredores de qualquer propriedade, sugere uma ligação entre a configuração do território e a não utilização do termo sertão. Afinal, não há o "desconhecido", o "misterioso", como ocorre na definição do termo. Mas, levando-se em conta um outro aspecto da definição do termo sertão, é possível arriscar uma outra hipótese, talvez um pouco mais consistente. Vamos a ela.

Entre as definições do termo sertão, coloca-se aquela que leva em conta o próprio impacto da utilização desta designação, ou seja, ao atribuir-se a um lugar qualquer a alcunha de sertão, pode-se estar, tão somente, promovendo uma certa preservação da área tal como ela está, evitando, com isto, sua ocupação num determinado momento e aguardando-se um possibilidade de valorização posterior.

No caso do Rio Grande do Sul coloca-se a questão da necessidade de ocupação imediata, não só para construir a fronteira entre as duas coroas ibéricas, como também para consolidar esta posse promovendo a efetiva exploração econômica da área. Todo esforço da coroa portuguesa dirigiu-se, num dado momento, para a garantia de povoamento e fixação da posse do território em questão, em seu benefício. Portugal preocupava-se com o povoamento pois sabia que só ele garantiria a defesa contra as investidas tanto dos espanhóis quanto dos índios que originalmente habitavam a área. 
Assim, era preciso promover os deslocamentos dentro do território, incentivar sua exploração, a fixação de populações que para cá foram trazidas com este intuito. Isto não seria possível se os habitantes tivessem receio de se deslocarem pela província.

Não quer isto dizer que houvesse uma intencionalidade consciente e explícita, por parte da coroa Portuguesa, em evitar a utilização do termo sertão ao produzir relatórios sobre a província de Rio Grande de São Pedro. Mas é de se notar que havia interesse - e necessidade - de um constante percorrer campos, vigiar a fronteira e permanecer alerta quanto ao que informava o extenso horizonte.

Por outro lado, é interessante notar como a literatura foi contagiada por esta relação com o espaço físico gaúcho. Ainda que o texto ficcional não tenha qualquer compromisso com uma coerência entre o que é representado e sua constituição real, não se encontra a adjetivação sertaneja em qualquer relato que se refira a espaços de parco povoamento ou de características que dificultam a ocupação. Se é verdade que a liberdade de criação do artista o isenta de qualquer preocupação quanto à correspondência entre real e ficcional, também é real a contaminação do artista pelos valores de seu meio, de seu tempo. A condição de fronteira aberta fez do Rio Grande do Sul um imenso campo de batalhas, o que determinou a varredura de toda sua extensão por seus habitantes, pela própria necessidade de defesa e sobrevivência. Os locais distantes e desconhecidos precisam ser revelados e incorporados às práticas cotidianas, como forma de consolidação da posse e manutenção dos espaços conquistados.

Os romances gaúchos falam deste constante percorrer terras, da "vocação" do gaúcho para a lida com o gado e dos grandes deslocamentos que esta atividade sempre impôs. Não há registro de estranhamento diante de distâncias muito acentuadas, ou de nomes de lugares desconhecidos. Esta atitude diferenciada do gaúcho, imposta pelas condições de existência desta unidade da federação, está presente na trama de vários romances. Não há estranhamento entre o morador do campo e o da cidade. Não há estranhamento no contato com paisagens ainda desconhecidas. Esta a atitude do gaúcho diante de tudo o que diz respeito ao seu meio.

Assim, a ausência do termo sertão nos textos literários do Rio Grande do Sul parece estar contaminada por este sentir-se em casa para o gaúcho, sempre que está se deslocando pelas amplas planícies do pampa. Não se percebe qualquer constrangimento em razão destes deslocamentos, como se eles já fossem uma condição a priori da própria identidade. A construção da fronteira e todas as guerras dela derivadas obrigavam a um constante vigiar.

Numa região caracterizada por extensões abertas e planas, a necessidade da vigilância não deixa de estar presente, antes reforça-se pelo espraiar-se do horizonte onde, a qualquer momento o inimigo poderia surgir.

\section{CONSIDERAÇÕES FINAIS}

O fato de não encontrarmos o termo sertão em textos literários do Rio Grande do Sul parece confirmar um dos sentidos a ele atribuídos, qual seja de que o sertão se define mais por uma condição de relação com outros espaços do que por qualquer característica intrínseca de um dado quadro natural.

Realmente, não parecem ser as condições físicas de um determinado lugar que o qualificam como sertão. Antes, são suas condições de existência que o fazem, a partir de sua integração - ou não - às dinâmicas espaciais de seu entorno.

No caso do Rio Grande do Sul, ao longo do processo de sua configuração enquanto território brasileiro, apesar de se tratar de um espaço em que as atividades produtivas se caracterizavam por grande dispersão, a condição de fronteira aberta foi determinante de uma atitude exploratória e vigilante de toda 
a extensão do estado, o que se reflete numa atitude diferenciada em relação ao território, que se expressa, por exemplo, na ausência do termo sertão em textos literários daquela unidade da federação.

E esta condição é revelada pelos textos literários da região, onde o território não assume a condição de espaço de mistério ou desconhecimento. Mesmo as condições ocasionalmente adversas do meio - a presença do Minuano, por exemplo - não assumem caráter depreciativo, porque este mesmo meio confere identidade e pertencimento aos seus habitantes.

\section{REFERÊNCIAS BIBLIOGRÁFICAS}

ASSIS BRASIL, Luiz Antônio de. Um quarto de légua em quadro. Diário do Doutor Gaspar de Froes, médico. $6^{\mathrm{a}}$ ed. Porto Alegre: Movimento, 1978. $192 \mathrm{p}$.

GUIMARÃES, Josué. Tempo de solidão. Rio de Janeiro: Sabiá, 1972. 239 p. (A ferro e fogo, 1)

MARTINS, Cyro. Porteira Fechada. 11 a ed. Porto Alegre: Movimento, 2001, 151 p.

MORAES, Antonio Carlos Robert. O sertão: um “outro” geográfico. In: Cadernos de Literatura Brasileira. "Euclides da Cunha". Edição especial comemorativa do centenário de "Os Sertões". Nos 13 e 14. Rio de Janeiro: Instituto Moreira Salles, 2002.

PELLEGRINI, Domingos. Terra Vermelha. 2a ed. São Paulo: Geração Editorial, 2003, 471p.

RODRIGUES, André Figueiredo. Os sertões proibidos da Mantiqueira: desbravamento, ocupação da terra e as observações do governador dom Rodrigo José de Meneses. Revista Brasileiras de História. Vol. 23 n 46. São Paulo, 2003.

WAIBEL, Leo. Capítulos de Geografia Tropical e do Brasil. 2a ed. anotada. Rio de Janeiro: Fundação Instituto Brasileiro de Geografia e Estatística, 1979, 326 p.

Recebido em maio de 2007

Aceito em agosto de 2007 